\title{
O descortinar de um diagnóstico de hematúria: relato de caso
}

Joana Simões Casanova, ${ }^{1}$ Alexandra Sousa ${ }^{2}$

\section{RESUMO}

Introdução: A prevalência dos sintomas do aparelho urinário baixo (LUTS) no homem aumenta com a idade e apresenta um enorme impacto na qualidade de vida, sendo uma das grandes causas de procura de cuidados médicos pelo homem adulto. De uma forma geral, perante um homem com LUTS dever-se-ão considerar as patologias que afetam a próstata, a uretra, a bexiga e o músculo detrusor.

Descrição do caso: Homem de 50 anos, soldador, com antecedentes pessoais de dislipidemia, um episódio de cólica renal, microlitíase renal e ex-fumador de 3,5 UMA.

Em outubro de 2012 recorre à consulta aberta por queixas de disúria, polaquiúria, hematúria terminal e dor hipogástrica, tendo sido considerado o diagnóstico de cistite com a indicação de cumprir antibioterapia, após colheita de urocultura. Perante resultado negativo da urocultura e por não apresentar prostração, febre nem corrimento purulento e pelos antecedentes de litíase renal, interpretou-se como segundo episódio de cólica renal.

Em agosto de 2013 apresenta-se na consulta programada com queixas de gotejamento final ao urinar e disúria terminal esporádica de longa evolução e hematúria em tira-teste. Foram requisitados o PSA total, sedimento urinário e ecografia vesicoprostática que, um mês mais tarde, veio a revelar uma volumosa lesão neoplásica da bexiga.

Comentário: Apesar da existência de fatores de risco (tabagismo prévio e idade superior a 35 anos) para o carcinoma da bexiga, este diagnóstico não foi considerado numa primeira fase. No acompanhamento deste quadro clínico surgiram outros fatores de confundimento, como os antecedentes pessoais de litíase renal e a presença de sintomas sugestivos de outras patologias mais frequentes nesta faixa etária.

O caso clínico exposto pelas autoras revela a complexidade do escrutínio diagnóstico dos LUTS no homem, tão comuns na consulta de medicina geral e familiar e que podem abranger um conjunto de patologias com orientações terapêuticas distintas.

Palavras-chave: Hematúria; Sintomas do Trato Urinário Inferior; Neoplasias da Bexiga.

\section{INTRODUÇÃO}

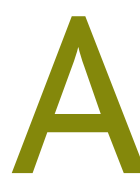
prevalência dos sintomas do trato urinário inferior (LUTS) do homem aumenta com a idade (cerca de $30 \%$ dos homens com mais de 65 anos) $)^{1}$ e pelo importante impacto que poderá ter na qualidade de vida do homem adulto ocupa uma grande parte das consultas de medicina geral e familiar.

$\mathrm{Na}$ presença destes sintomas existe uma forte tendência para direcionarmos as nossas hipóteses de diagnóstico para a hiperplasia benigna da próstata, responsável pela obstrução do trato de saída da bexiga. ${ }^{2}$ No

'Médica Interna de Medicina Geral e Familiar - Unidade de Saúde Familiar Oceanos, Unidade Local de Saúde de Matosinhos

${ }^{2}$ Médica Assistente Graduada Sénior em Medicina Geral e Familiar - Unidade de Saúde Familiar Leça, Unidade Local de Saúde de Matosinhos entanto, é necessário seguir um raciocínio cuidadoso de forma a excluir as patologias que envolvem todo o aparelho urinário, envolvendo: a próstata, uretra, bexiga e os esfíncteres. ${ }^{3}$

Neste contexto, o diagnóstico de neoplasia da bexiga, na maioria das vezes, é um diagnóstico de exclusão por ser menos frequente do que os outros diagnósticos responsáveis por LUTS. No presente caso clínico, a probabilidade de tal diagnóstico seria ainda menor pela existência de alguns fatores de confundimento descritos ao longo deste artigo. Por essa baixa probabilidade, as autoras consideram pertinente a divulgação deste caso clínico e relembrar os passos a seguir no escrutínio diagnóstico de um homem adulto com LUTS. 


\section{DESCRIÇÃO DO CASO}

\section{Identificação}

J.F.N.Q. é um utente caucasiano, tem 50 anos de idade e é natural e residente no concelho de Matosinhos. Tem o sexto ano de escolaridade e a única profissão que exerceu até ao momento foi a de soldador. É casado e tem um filho e uma neta. $\mathrm{O}$ seu agregado familiar é constituído por esposa e sogros, sendo uma família do tipo alargada que pertence à classe III de Grafar.

A Figura 1 revela o genograma familiar com a representação da psicofigura de Mitchell do agregado familiar. Revela os antecedentes familiares mais relevantes, destacando-se a ausência de patologia oncológica do sistema urinário e a presença de um caso de carcinoma (do colón) num parente de primeiro grau (mãe do utente).

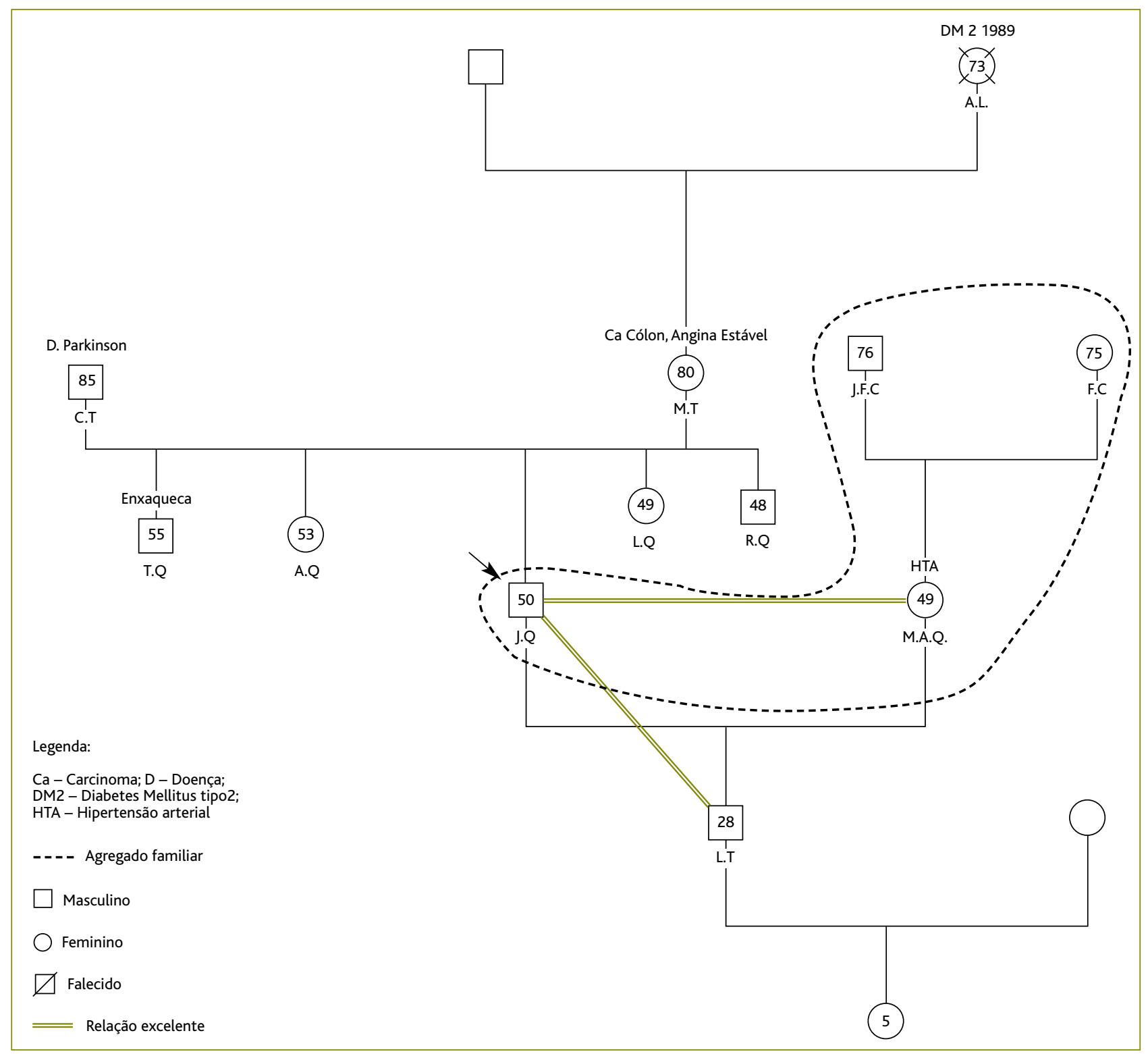

Figura 1. Genograma e psicofigura de Mitchell. Data: 07.11.2013 


\section{Antecedentes pessoais}

J.F.N.Q. é frequentador das consultas de medicina geral e familiar desde o ano 2000. Por ordem cronológica, apresenta os seguintes antecedentes pessoais: no ano 2000, ocorrência de episódio de paralisia facial periférica e realizado diagnóstico de surdez neurossensorial bilateral, iniciando seguimento em consulta externa de otorrinolaringologia. Em 2010 é feito o diagnóstico de diabetes mellitus tipo 2 que se mantém controlada com dieta e atividade física e, ainda, dislipidemia medicada e controlada com anti-dislipidémico. Em maio de 2011 sofre um episódio de cólica renal aguda, documentado em ecografia renal. No ano de 2013, no âmbito do rastreio do cancro colorretal, é submetido a uma colonoscopia que revela um pólipo de $4 \mathrm{~mm}$ (adenoma com displasia de baixo grau).

Sedentário, ex-fumador há 27 anos (carga tabágica 3,5 UMA), sem hábitos etílicos ou consumo de substâncias de abuso.

J.Q. nega antecedentes de tuberculose urinária, infeção crónica do aparelho urinário e schistosomíase urinária. Não existia, ainda, história de radiação pélvica e de tratamentos com ciclofosfamida e toma de pioglitazona para o controlo da diabetes mellitus tipo 2 .

\section{História da doença atual}

\section{9 de outubro de 2012 - Consulta aberta}

O utente dirigiu-se à consulta aberta por apresentar hematúria terminal, dor hipogástrica, disúria e polaquiúria com 12 horas de evolução. Não apresentava náuseas, vómitos, dor lombar ou febre. Ao exame objetivo encontrava-se corado, apirético e, à palpação abdominal, sem alterações de relevo, com Murphy renal negativo. Realizou tira-teste à urina que evidenciou hematúria isolada.

Perante este quadro clínico, foi considerada como primeira hipótese de diagnóstico uma infeção do trato urinário (ITU). No seu diagnóstico diferencial foram tidas em conta as seguintes patologias: prostatite, orquiepididimite ou uretrite.

Por o utente não apresentar queixas de dor escrotal nem corrimento uretral, diminuiu a probabilidade de se tratar de uma orquiepididimite e uretrite.

$\mathrm{Na}$ ausência de febre, calafrios e mal-estar generalizado, a prostatite foi considerada como menos provável. No entanto, tendo em conta a frequente coexistên- cia de prostatite e cistite no homem e a dificuldade em distingui-las, a médica de família prescreveu ciprofloxacina $500 \mathrm{mg}$ duas vezes por dia, durante sete dias e requisitou urocultura com a indicação de colher a amostra de urina antes da primeira toma de antibiótico. Após resultado, seria contactado caso fosse necessário alterar a atitude terapêutica.

Três dias após a consulta foi obtido o resultado da urocultura que se revelou negativa. Ao consultar o processo clínico, estava descrito em duas ecografias renais (nos anos de 2010 e 2012) a presença de microlitíase e história de um episódio de cólica renal, o que configurou mais um dado clínico e mais uma hipótese diagnóstica: cólica renal. O doente foi contactado e referia desaparecimento das queixas. Tendo em conta estes antecedentes, as queixas do doente, o achado de hematúria isolada na tira-reativa e uma urocultura negativa, foi interpretado como um episódio de cólica renal aguda com resolução clinica espontânea.

\section{9 de dezembro de 2012 - Serviço de Atendimento de Situações de Urgência (SASU)}

O utente recorreu ao SASU por apresentar dor abdominal generalizada, sem irradiação e náuseas, com uma semana de evolução. Referia ter tido vómitos nos primeiros dias da doença que remitiram e apresentava disúria e hematúria com aparecimento nas últimas 24 horas, sem febre. Existia história de conviventes com gastroenterite.

Ao exame objetivo apresentava-se com bom estado geral, mucosas coradas e hidratadas, hemodinamicamente estável, apirético, com dor abdominal à palpação superficial, sem defesa, sem massas ou organomegalias palpáveis e sinal de Murphy renal negativo.

Realizou de novo tira-teste à urina que evidenciou apenas presença de sangue. Foi interpretado como cólica renal e teve alta com recomendações para analgesia e vigilância dos sinais de alarme.

\section{3 de janeiro de 2013 - Consulta programada}

Na sua consulta de vigilância da diabetes mellitus tipo 2, o utente referiu queixas de lombalgias episódicas do tipo inflamatório. Nas análises realizadas nos 13 dias anteriores à consulta não apresentava alteração da função renal (creatinina: 0,8mg/dL; ureia: $27 \mathrm{mg} / \mathrm{dL}$ ).

Perante o conhecimento de um segundo episódio 
de cólica renal decorrido no mês anterior e a presença de lombalgias, apesar de uma função renal normal, foi requisitada ecografia renal para excluir complicações associadas a urolitíase, nomeadamente o aumento do tamanho dos cálculos já conhecidos, uma possível obstrução e hidronefrose.

\section{1 de agosto de 2013 - Consulta programada}

Na consulta programada queixou-se de jacto fino e gotejante e disúria terminal esporádica com 3 meses de duração. Negava hematúria e febre. A tira-teste reativa revelava vestígios de sangue.

Foi realizada a consulta de vigilância e, na sequência das queixas apresentadas que teriam um impacto importante na sua qualidade de vida, foi feito um pedido de ecografia vesicoprostática, urina tipo II e PSA total.

\section{3 de setembro de $\mathbf{2 0 1 3}$ - Consulta aberta}

O utente recorreu à consulta aberta com os resultados dos exames complementares de diagnóstico. O sedimento urinário e o valor de PSA, realizados a 26 de agosto de 2013, estavam normais. A ecografia renal, realizada a 12 de setembro de 2013, evidenciava dois quistos sinusais de $11 \mathrm{~mm}$ e $20 \mathrm{~mm}$ e microcálculos escassos e bilaterais, não provocando obstrução das árvores excretoras. Na mesma data foi efetuada uma ecografia vesicoprostática que identificou: "Uma volumosa lesão neoplásica da bexiga, medindo o seu maior diâmetro $45 \mathrm{~mm}$ e com volume de $54 \mathrm{cc}$. Bexiga com parede discretamente espessada com quadro de bexiga de esforço. Observa-se uma glândula prostática ligeiramente aumentada de dimensões, estimando-se o seu peso em 35 gramas. Os contornos são regulares e a ecoestrutura homogénea. Resíduo pós-miccional nulo".

Perante o diagnóstico, ainda não confirmado por biópsia e cistoscopia, a médica de família contactou o serviço de urologia do hospital da área de residência e referenciou-o de forma urgente para a consulta externa.

\section{Outubro de 2013 - Em consulta hospitalar}

O utente foi submetido a duas recessões transuretrais completas com diagnóstico histológico de "Carcinoma urotelial sem invasão da submucosa, de baixo grau com focos de alto grau".

Atualmente encontra-se vigiado na consulta de uro- logia sob tratamentos de mitomicina C (MMC) de manutenção e vigilância por cistoscopia.

A figura 2 representa a evolução cronológica dos acontecimentos desde os primeiros sintomas até ao diagnóstico final.

\section{COMENTÁRIO}

Na região Norte do país, em 2008, o carcinoma da bexiga era o quinto tumor mais frequente no sexo masculino (7,3\% do número total de casos), depois dos tumores da próstata, do pulmão, cólon e estômago. ${ }^{4}$

$\mathrm{O}$ fator de risco ambiental mais conhecido para o carcinoma da bexiga é o consumo de tabaco (atual ou prévio). Os fumadores apresentam um risco de desenvolver carcinoma da bexiga sete vezes superior ao risco de um não fumador. ${ }^{5}$

Nos países industrializados, até $10 \%$ dos cancros com essa localização são causados por exposição ocupacional a carcinogéneos, como: aminas aromáticas, agentes da indústria automóvel, maquinarias e peles. ${ }^{5}$

Outros fatores de risco encontrados na bibliografia incluem: pertencer ao sexo masculino e de etnia caucasiana, idade superior a 35 anos, história familiar, contacto com água contaminada com arsénico, infeção crónica da bexiga, tuberculose geniturinária, algaliação crónica e schistosomíase urinária e utilização de alguns fármacos de risco (e.g., ciclofosfamida, pioglitazona). ${ }^{5-7}$

O utente apresentado neste caso clínico é um ex-fumador de carga tabágica baixa e a sua profissão (soldador) não representa uma profissão de risco por exposição a estes componentes. Para além disso, a ausência de história familiar, de antecedentes pessoais e medicação de risco diminuiu ainda mais a probabilidade de se chegar ao diagnóstico de diagnosticar carcinoma da bexiga neste utente. Desta forma, apenas a idade (superior a 35 anos) é o único fator de risco a salientar.

O achado clínico mais frequentemente encontrado nesta doença é a hematúria microscópica ou macroscópica assintomática ou associada a disúria e a sintomas do trato urinário inferior do homem adulto (LUTS). ${ }^{5}$

A presença de sintomas de armazenamento refratários ao tratamento sintomático é indicativo de carcinoma in situ, enquanto os sintomas de esvaziamento 


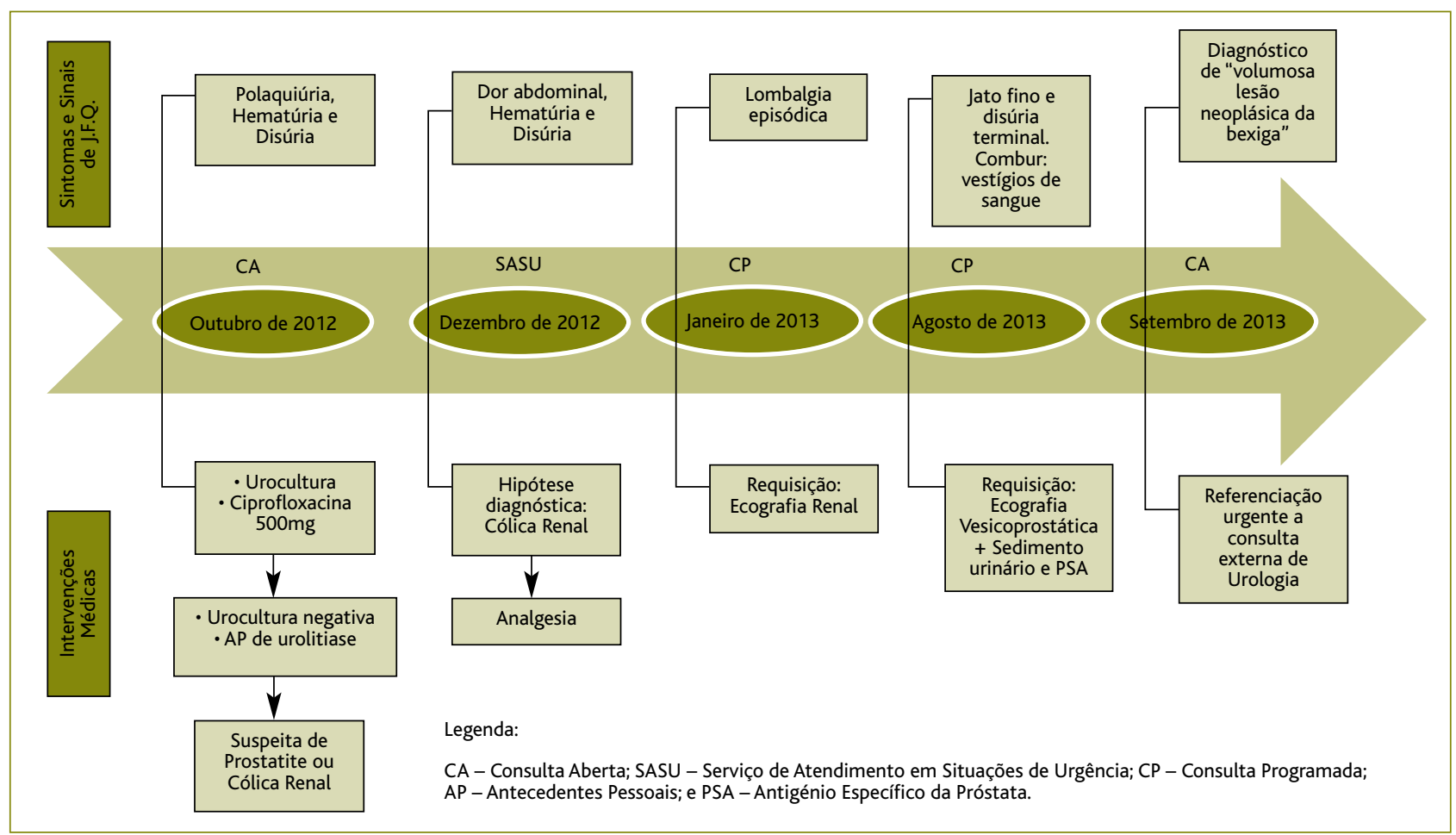

Figura 2. Linha temporal da sintomatologia e sinais do utente e as intervenções médicas efetuadas nas visitas à unidade de saúde familiar.

são mais prevalentes nos tumores localizados próximo da uretra ou do colo vesical. ${ }^{8} \mathrm{Na}$ doença avançada pode haver queixas de dor lombar causadas por obstrução ureteral ou dor abdominal ou óssea relacionadas com metastização à distância. ${ }^{5}$

Ao exame físico raramente são encontrados sinais da doença localizada; no entanto, quando a doença está em estádio avançado pode ser palpável uma massa supra-púbica. ${ }^{5}$

Fazendo uma análise retrospetiva das queixas do nosso utente ao longo das várias consultas, a hematúria macroscópica, a disúria e os sintomas de LUTS constituíam as suas principais queixas.

$\mathrm{Na}$ avaliação de uma hematúria, confirmada em tirateste reativa da urina, deveremos pensar em causas renais e extrarrenais, sendo estas últimas as mais frequentes, correspondendo a $60 \%$ dos casos. ${ }^{9}$ Nos primeiros contactos com o J.F.N.Q., as hipóteses consideradas mais prováveis eram de etiologia não renal: cistite aguda ou prostatite aguda, cólica renal aguda e hiperplasia benigna da próstata.

A distinção entre cistite e prostatite não é muito cla- ra e, assim, a hipótese de diagnóstico de prostatite deve ser sempre equacionada. Pode apresentar-se de diversas formas, desde queixas subtis até uma infeção grave. As manifestações clínicas mais comuns são disúria, urgência miccional, polaquiúria, noctúria, desconforto perineal e dor lombar, hematúria e ejaculação dolorosa, febre, calafrios e mal-estar. ${ }^{10-11}$

A probabilidade de existir uma prostatite concomitante é superior nos casos de ITU febril, ${ }^{12}$ tal facto não se constatou em nenhum contacto com este utente. Outro dado a ter em conta no diagnóstico clínico de uma prostatite é o toque retal, pois tipicamente a glândula encontra-se dolorosa, quente e edemaciada. ${ }^{13}$ No entanto, esta manobra semiológica nunca foi realizada durante o exame objetivo deste utente, o que dificultou a exclusão deste diagnóstico.

Um dado epidemiológico que poderá contribuir para a distinção entre estas duas patologias é a idade. A partir dos 50 anos, a incidência de ITU no homem aumenta devido ao alargamento da próstata com consequente obstrução do trato de saída da bexiga e presença de urina residual. Outros fatores de risco para ITU mais fre- 
quentes no homem adulto são a instrumentação do trato urinário, imobilidade ou diminuição da atividade e diminuição do volume de secreções prostáticas. ${ }^{10}$

Pela dificuldade neste diagnóstico diferencial, o tratamento antibiótico empírico recomendado para uma ITU no homem passa por uma quinolona pela sua maior penetração no tecido prostático. ${ }^{11-12}$ Apesar de não existir evidência clara sobre o melhor período do tratamento, o consenso nas normas de orientação clínica aponta para um período mínimo de duas ${ }^{12}$ até quatro semanas. ${ }^{11}$

Não existe nenhuma evidência para sugerir o melhor método de diagnóstico de infeção urinária bacteriana nos homens. Em todas as suspeitas de ITU no homem deve ser colhido um exame bacteriológico de urina prévio ao tratamento. ${ }^{14} \mathrm{~A}$ obtenção de uma amostra de urina limpa de urina nos homens é mais fácil do que em mulheres e uma contagem de colónia de $\geq 10^{3} \mathrm{ufc} / \mathrm{ml}$ pode ser suficiente para diagnosticar a infeção urinária num homem com sinais e sintomas. ${ }^{12}$

Conhecendo estes factos, a médica de família prescreveu uma quinolona (ciprofloxacina), recomendando a colheita de urina prévia à primeira toma de antibioterapia. Uma vez que o resultado da urocultura foi negativo, foi de facto ponderada a possibilidade de se estar perante uma prostatite, visto que nesta situação pode ser encontrada urocultura sem alterações..$^{15}$ No entanto, o conhecimento dos antecedentes de urolítiase, de um episódio de cólica renal prévio e a ausência de febre, calafrios e dor pélvica aumentou a probabilidade de se tratar de um segundo episódio de cólica renal aguda.

A cólica renal é a principal manifestação da urolitíase e requer uma abordagem assertiva. Em $90 \%$ dos casos de cólica renal, o uso de uma tira de teste reativa demonstrará hematúria, ${ }^{16}$ como apresentado no nosso caso clínico. Habitualmente, manifesta-se por uma dor súbita na região lombar ou flanco com irradiação para os genitais e sem qualquer posição de alívio. Por vezes, o doente apresenta vómitos e febre que deverão ser motivos de referenciação ao serviço de urgência. ${ }^{16}$ No caso exposto, este quadro clínico não esteve presente; em vez disso o doente manifestou sintomas urinários baixos (polaquiúria, disúria e dor no hipogastro) que são mais frequentes quando os cálculos se localizam na porção terminal do ureter ou na transição para a bexi- ga, podendo assim simular um quadro de cistite. ${ }^{16-17} \mathrm{~A}$ possibilidade de existência de complicações agudas e irreversíveis de um rim obstruído não foi equacionada após a primeira consulta (29 de outubro de 2012) porque o doente se apresentou assintomático nos três dias seguintes. A médica de família só tomou conhecimento do segundo episódio de cólica renal diagnosticado no S.A.S.U. no mês seguinte e, pelas queixas de lombalgias intermitentes, foi-lhe requisitada uma ecografia renal.

Outro dado contra a existência de uma ITU ou prostatite é a ausência de leucocitúria e nitritos na tira-teste urinária. ${ }^{18}$

A presença de LUTS de armazenamento associados a hematúria macroscópica com uma análise de tirateste apenas positiva para a presença de eritrócitos sugere, como hipóteses diagnósticas mais prováveis, patologias não infecciosas com atingimento do aparelho urinário. ${ }^{19}$ Um doente que se apresente com hematúria macroscópica tem uma probabilidade de $20 \%$ de apresentar carcinoma da bexiga, pelo que se torna necessário considerar estes doentes como possíveis portadores de neoplasias. ${ }^{5,20}$

É também fundamental questionar o doente na tentativa de relacionar o tempo de aparecimento da hematúria na duração do jacto. A hematúria poderá ser classificada em inicial (patologia ao nível da uretra prostática), total (lesão na bexiga ou no aparelho urinário superior) e terminal (lesão ao nível do colo vesical). A hematúria que se acompanha de coágulos tem geralmente origem extraglomerular. ${ }^{9,20}$ No doente em causa, a hematúria era descrita como se fosse terminal, aumentando a probabilidade de se tratar de uma patologia envolvendo o colo vesical.

Definindo uma linha temporal deste caso clínico (figura 2), ao longo de cerca de 10 meses, o nosso utente apresentou-se quatro vezes na unidade de saúde com um intervalo significativo entre as consultas e com queixas sobreponíveis. Na última consulta, por aparecimento de uma queixa de novo do tipo de esvaziamento (jacto fino e gotejante) associada a disúria e hematúria microscópica, foi ponderada a possibilidade de se tratar de patologia prostática e vesical. Nesse sentido, foi requisitada uma ecografia vesicoprostática suprapúbica que, no contexto da hipertrofia benigna prostática, é um método não invasivo muito útil para a 


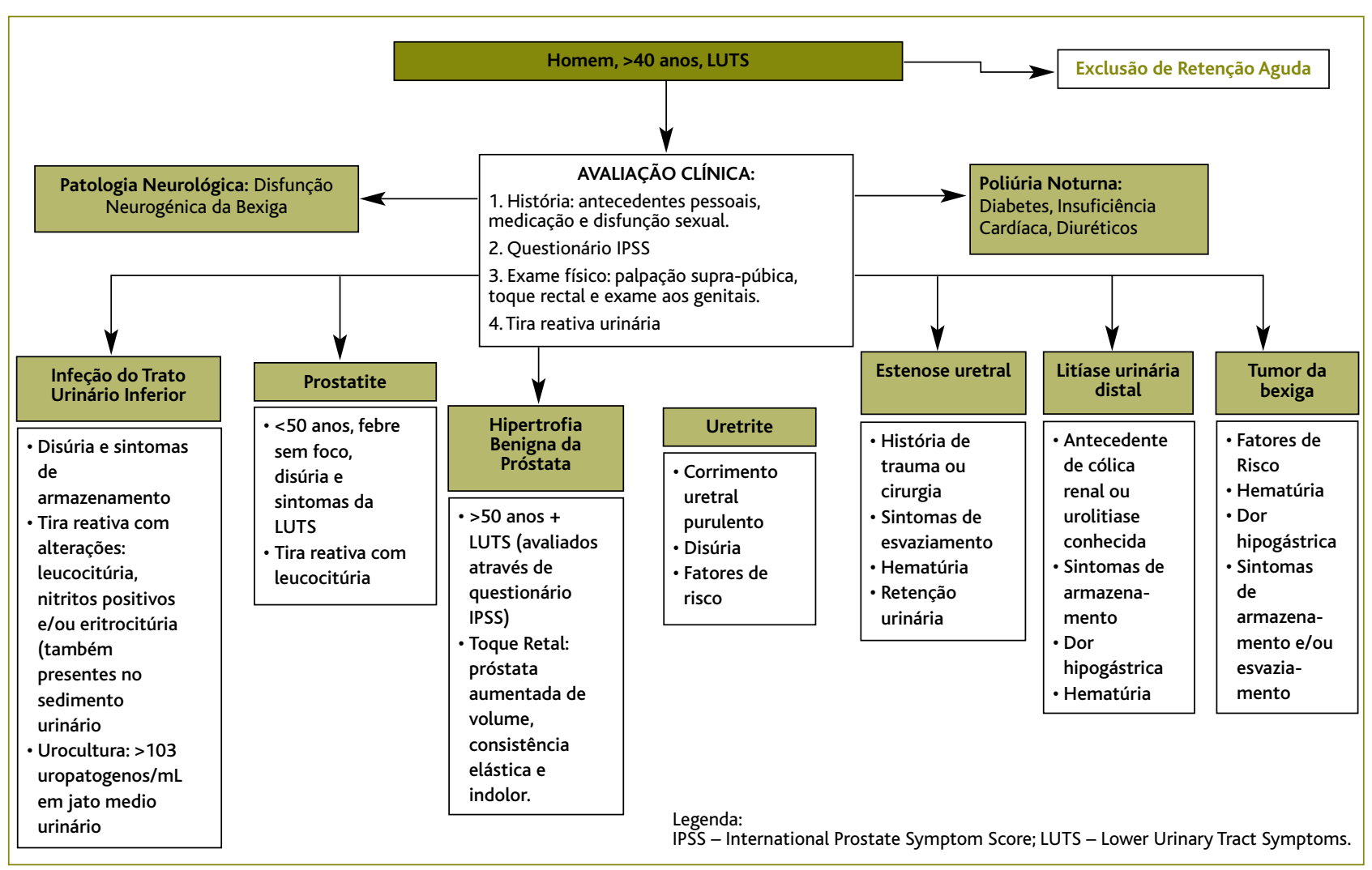

Figura 3. Diagnóstico clínico das principais causas de LUTS no homem adulto. ${ }^{1-3}$

estimativa do volume prostático e resíduo pós-miccional e na identificação de complicações a nível vesical, como divertículos, cálculos ou bexiga trabeculada ("de esforço"). Também permite fazer o diagnóstico diferencial com carcinoma da próstata, carcinoma da bexiga e cálculo no ureter distal. ${ }^{21}$ Para complementar 0 estudo da patologia prostática foi também pedido PSA total. O sedimento urinário foi requisitado com o objetivo de estudar a hematúria persistente.

A hipertrofia benigna da próstata caracteriza-se não só pelos sintomas no trato urinário inferior (LUTS) secundários ao aumento do volume da glândula prostática e consequente obstrução do fluxo urinário, ${ }^{2}$ como a polaquiúria e o jacto fino descritos pelo nosso utente, mas também por disúria e hematúria numa fase avançada da doença. ${ }^{20}$ Pelo conhecimento desta apresentação clínica, esta hipótese diagnóstica foi ponderada na penúltima consulta do doente e requisitados os exames que revelaram o diagnóstico final.
O exame gold-standard para o diagnóstico e vigilância do carcinoma da bexiga é a cistoscopia, exame apenas disponível nos cuidados de saúde secundários. A ecografia vesical é um exame complementar de diagnóstico de baixo custo e acessível aos cuidados de saúde primários; no entanto, tem importantes limitações na deteção de neoplasias planas, com menos de $5 \mathrm{~mm}$ ou próximas do colo vesical. Com a requisição de uma ecografia por via transretal, é possível contornar essas limitações e aumentar a sensibilidade deste exame. ${ }^{21} \mathrm{Al}-$ guns autores defendem que a ecografia é um exame custo-efetivo e deve ser o primeiro exame de imagem a ser pedido em contexto de investigação de uma hematúria com elevada suspeita de neoplasia da bexiga e a confirmação do diagnóstico deverá ser por cistoscopia. $^{22}$

Para além da necessidade de intervenção na cessação tabágica como estratégia de prevenção primária desta neoplasia, também a deteção precoce da neo- 
plasia da bexiga é uma importante medida de redução da mortalidade associada a esta patologia, tendo impacto na história natural desta doença. ${ }^{23}$ Apesar deste facto, sabe-se que os programas de rastreio desta neoplasia (através do sedimento da urina, citologia da urina e biomarcadores urinários) não foram considerados eficazes. A U.S. Preventive Services Task Force, numa revisão de 2011, declara que não existe evidência suficiente que permita encontrar um equilíbrio entre os benefícios e malefícios do rastreio sistematizado a doentes assintomáticos. ${ }^{6}$

$\mathrm{Na}$ avaliação deste utente surgiram alguns fatores de confundimento que contribuíram para a baixa suspeição de carcinoma da bexiga, permitindo alertar para a necessidade de se efetuar uma avaliação urológica periódica em doentes com queixas de hematúria ou LUTS e com uma doença benigna subjacente já conhecida que poderá justificar a sintomatologia (como o caso da litíase renal), pois o risco de uma neoplasia concomitante mantém-se nestes doentes. ${ }^{7}$

O grande desafio para o médico de família no diagnóstico desta neoplasia passa por não assumir apenas as patologias mais frequentes que apresentam uma clínica semelhante como as mais prováveis e manter sempre um elevado grau de suspeição de neoplasia da bexiga perante um doente com fatores de risco e hematúria persistente.

Com este caso pretendeu-se ainda chamar a atenção para a complexidade da abordagem diagnóstica dos sintomas do trato urinário inferior (LUTS) em adultos do género masculino. Nesse sentido, as autoras elaboraram um algoritmo de diagnóstico clínico baseado nas normas de orientação clínica internacionais mais recentes (figura 3) que aborda outras patologias que deverão também ser excluídas perante um homem adulto com queixas de LUTS, nomeadamente: causas de poliúria noturna, disfunção neurogénica da bexiga, disfunção do detrusor (hipo ou hiperatividade) e ainda estenose uretral.

\section{REFERÊNCIAS BIBLIOGRÁFICAS}

1. National Institute for Health and Care Excellence. Lower urinary tract symptoms: the management of lower urinary tract symptoms in men [Internet]. London: Royal College of Physicians; 2010 May [cited 2013 Nov 8]. Available from: https://www.nice.org.uk/guidance/cg97/resources/guidance-lower-urinary-tract-symptoms-pdf

2. Gravas S, Bachmann A, Descazeaud A, Drake M, Gratzke C, Madersba- cher S, et al. Guidelines on the management of non-neurogenic male lower urinary tract symptoms (LUTS), incl. benign prostatic obstruction (BPO) [Internet]. European Association of Urology; 2014 [cited 2014 Nov 05].Available from: http://uroweb.org/wp-content/uploads/ Non-Neurogenic-Male-LUTS_2705.pdf

3. British Association of Urological Surgeons. Commissioning guide: lower urinary tract symptoms [Internet]. London: The Royal College of Surgeons of England; 2013 May [cited 2013 Nov 8]. Available from: http:// www.rcseng.ac.uk/healthcare-bodies/docs/published-guides/luts

4. Registo Oncológico Regional do Norte. Os tumores mais frequentes no sexo masculino e feminino em 2008 [Internet]. RORENO; 2010 [cited 2015 Fev]. Available from: http://www.roreno.com.pt/pt/estatisticas.html

5. Sharma S, Ksheersagar P, Sharma P. Diagnosis and treatment of bladder cancer. Am Fam Physician. 2009;80(7):717-23.

6. Moyer VA, U. S. Preventive Services Task Force. Screening for bladder cancer: U. S. Preventive Services Task Force recommendation statement. Ann Intern Med. 2011;155(4):246-51.

7. Davis R, Jones JS, Barocas DA, Castle EP, Lang EK, Leveillee RJ, et al. Diagnosis, evaluation and follow-up of asymptomatic microhematuria (AMH) in adults: AUA guideline. J Urol. 2012;188 (6 Suppl):2473-81.

8. Witjes JA, Compérat E, Cowan NC, De Santis M, Gakis G, Lebrét T, et al. Guidelines on non-muscle-invasive bladder cancer [Internet]. European Association of Urology; 2014 [cited 2014 Nov 05]. Available from: http://uroweb.org/wp-content/uploads/07-Muscle-Invasive-BC_LRLV2-May-14th.pdf

9. Moreno Elola-Easo C. Orina oscura: hematuria. Landa Goñi J, editor. Guía de actualización clínica en nefrourología [Internet]. Barcelona: SemFYC; 2003 [cited 2014 Jan 10]. p. 37-40. ISBN 8496216187. Available from: http://www.semfyc.es/es/biblioteca/virtual/detalle/ Guia_Act_Clinica_Nefrourologia/

10. Lebovitch S, Pontari MA. Prostatitis and lower urinary tract infections in men. In Hanno PM, Guzzo PJ, Malkovitcz SB, Wein AJ, editors. Penn clinical manual of urology. Saunders; 2007. p. 177-88. ISBN 9781455753598

11. Scottish Intercollegiate Guidelines Network. Management of suspected bacterial urinary tract infection in adults: a national clinical guideline [Internet]. Edinburgh: SIGN; 2012 [cited 2013 Nov 8]. Available from: http://www.sign.ac.uk/pdf/sign88.pdf

12. Grabe M, Bartoletti R, Bjerklund-Johansen TE, Çek HM, Pickard RS, Tenke $\mathrm{P}$, et al. Guidelines on urological infections [Internet]. European Association of Urology; 2014 [cited 2014 Nov 05]. Available from: http://uroweb.org/wp-content/uploads/19-Urological-infections_ LR.pdf

13. Sharp VJ, Takacs EB, Powell CR. Prostatitis: diagnosis and treatment. Am Fam Physician. 2010;82(4):397-406.

14. Direção-Geral da Saúde. Terapêutica das infeções do aparelho urinário (comunidade): norma da DGS n 015/2011, de 30/08/2011. Lisboa: DGS; 2011 [cited 2013 Nov 8]. Available from: http://www.dgs.pt/normas-clinicas/normas-clinicas.aspx

15. Lee SJ, Lee DH, Park YY, Shim BS. A comparative study of clinical symptoms and treatment outcomes of acute bacterial prostatitis according to urine culture. Korean J Urol. 2011;52(2):119-23.

16. Buitrago-Ramírez F, Mascías-Castillo S. Nefrolitiasis: crisis renourete- 
ral. In Landa Goñi J, editor. Guía de actualización clínica en nefrourología [Internet]. Barcelona: SemFYC; 2003 [cited 2014 Jan 10]. p. 8192. ISBN 8496216187. Available from: http://www.semfyc.es/es/biblioteca/virtual/detalle/Guia_Act_Clinica_Nefrourologia/

17. Gomes J, Vendeira P, Ribau U, Reis M. Urolitíase e cólica renal: perspectiva terapêutica em urologia [Urolithiasis and renal colic: a treatment approach in urology]. Acta Med Port. 2002;15(5):369-80. Portuguese

18. Devillé WL, Yzermans JC, van Duijn NP, Bezemer PD, van der Windt DA, Bouter LM. The urine dipstick test useful to rule out infections: a metaanalysis of the accuracy. BMC Urol. 2004;4:4.

19. Simerville JA, MaxtedWC, Pahira JJ. Urinalysis: a comprehensive review. Am Fam Physician. 2005;71(6):1153-62.

20. Milheiro A, Prisco R. Hematúria [Hematuria]. Act Med Port. 1999;12(13):13-7. Portuguese

21. Leyendecker JR, Francis IR, Casalino DD, Arellano RS, Baumgarten DA, Curry NS, et al. Expert panel on urologic imaging: ACR appropriateness criteria ${ }^{\circledR}$ follow-up imaging of bladder carcinoma [Internet]. Reston (VA): American College of Radiology (ACR); 2009. Available from: http://www.guideline.gov/content.aspx?id=48293.

22. Rafique $M$, Javed $A A$. Role of intravenous urography and transabdominal ultrasonography in the diagnosis of bladder carcinoma. Int Braz J Urol. 2004; 30(3):185-91.

23. Smith A, Balar AV, Milowsky MI, Chen RC. Bladder cancer. In Niederhuber JE, Armitage JO, Doroshow JH, Kastan MB, Tepper JE. Abeloff's clinical oncology. 5th ed. Philadelphia: Churchill Livingstone; 2014. p. 1445-62. ISBN 9781455728657

\section{CONFLITO DE INTERESSES}

As autoras declaram não ter conflitos de interesses.

\author{
ENDEREÇO PARA CORRESPONDÊNCIA \\ Joana Simões Casanova \\ Praça Luís de Camões Bloco, 2 \\ 4490-441 Póvoa de Varzim \\ E-mail: j.simoescasanova@gmail.com
}

Recebido em 05-11-2014

Aceite para publicação em 25-04-2015

\section{ABSTRACT}

\section{DIAGNOSING HEMATURIA IN A MIDDLE-AGED MAN: A CASE REPORT}

Introduction: The prevalence of lower urinary tract symptoms (LUTS) increases with age. They have significant impact on quality of life and commonly cause adults to seek medical care. When a middle-aged man presents with LUTS, we must consider diseases that affect the prostate, urethra, bladder and detrusor muscle.

Case report: A 50 year-old male welder, with a previous history of dyslipidemia, 3,5 pack-years of smoking, and an episode of renal colic with renal microlithiasis came to his Family Physician in October 2012. He complained of dysuria, urinary frequency, terminal hematuria, and hypogastric pain. A diagnosis of cystitis was made and antibiotic therapy was prescribed after obtaining a urine culture. The urine culture was negative. In the absence of prostration, fever, and purulent discharge, and given a previous history of urolithiasis, this episode was reinterpreted as a second episode of renal colic.

In August 2013, the patient presented with terminal dribbling, sporadic dysuria, and hematuria on urine dipstick analysis. An assay of total prostate specific antigen, an analysis of urinary sediment, and a transabdominal vesicoprostatic ultrasound were ordered. One month later a bulky neoplastic lesion of the bladder was found on ultrasound examination.

Comment: Despite the presence of risk factors for bladder carcinoma (previous smoking and age over 35 years), this diagnosis was not considered at the initial consultation. On follow-up, other confounding factors emerged, including a past history of renal stones and the presence of symptoms suggestive of other diseases more common in this age group. The case report explores the complexity of the differential diagnosis of LUTS in an adult male. This is a common complaint in Family Medicine consultations, pointing to a set of disorders with defined diagnostic and therapeutic guidelines.

Keywords: Hematuria; Lower urinary tract symptoms; Urinary bladder neoplasms. 